\title{
Providing male rats deficient in iron and n-3 fatty acids with iron and alpha-linolenic acid alone affects brain serotonin and cognition differently from combined provision
}

\author{
Jeannine Baumgartner ${ }^{1,2^{*}}$, Cornelius M Smuts ${ }^{1}$ and Michael B Zimmermann ${ }^{2}$
}

\begin{abstract}
Background: We recently showed that a combined deficiency of iron (ID) and n-3 fatty acids (n-3 FAD) in rats disrupts brain monoamine metabolism and produces greater memory deficits than ID or n-3 FAD alone. Providing these double-deficient rats with either iron (Fe) or preformed docosahexaenoic acid (DHA)/eicosapentaenoic acid (EPA) alone affected brain monoamine pathways differently from combined repletion and even exacerbated cognitive deficits associated with double-deficiency. Iron is a co-factor of the enzymes responsible for the conversion of alpha-linolenic acid (ALA) to EPA and DHA, thus, the provision of ALA with Fe might be more effective in restoring brain EPA and DHA and improving cognition in double-deficient rats than ALA alone.

Methods: In this study we examined whether providing double-deficient rats with ALA and Fe, alone or in combination, can correct deficits in monoamine metabolism and cognition associated with double-deficiency. Using a $2 \times 2$ design, male rats with concurrent ID and n-3 FAD were fed an Fe + ALA, Fe + n-3 FAD, ID + ALA, or ID + n-3 FAD diet for 5 weeks (postnatal day 56-91). Biochemical measures, and spatial working and reference memory (using the Morris water maze) were compared to age-matched controls.

Results: In the hippocampus, we found a significant Fe $\times$ ALA interaction on DHA: Compared to the group receiving ALA alone, DHA was significantly higher in the Fe + ALA group. In the brain, we found significant antagonistic Fe $\times$ ALA interactions on serotonin concentrations. Provision of ALA alone impaired working memory compared with age-matched controls, while in the reference memory task ALA provided with Fe significantly improved performance.
\end{abstract}

Conclusion: These results indicate that providing either iron or ALA alone to double-deficient rats affects serotonin pathways and cognitive performance differently from combined provision. This may be partly explained by the enhancing effect of Fe on the conversion of ALA to EPA and DHA.

Keywords: Alpha-linolenic acid, Cognition, Iron, Monoamines, n-3 fatty acids

\footnotetext{
* Correspondence: jeannine.baumgartner@gmail.com

'Centre of Excellence for Nutrition, North-West University, Private Bag X6001, 2520 Potchefstroom, South Africa

${ }^{2}$ Laboratory of Human Nutrition, Institute of Food, Nutrition and Health, ETH

Zürich, Zürich, Switzerland
} 


\section{Background}

Children and adolescents from low-income countries may suffer from both, iron (Fe) deficiency (ID) and n-3 fatty acid deficiency (n-3 FAD) due to poor quality diets during periods of rapid growth $[1,2]$. Fe is a co-factor for enzymes involved in cell division and the synthesis of neurotransmitters, myelin and biologically active lipid mediators and is therefore crucial for normal brain development and functioning [3-7]. Similarly to Fe, the long-chain polyunsaturated n-3 FA docosahexaenoic acid (DHA, 22:6n-3) and eicosapentaenoic acid (EPA, 20:5n-3) play important roles in neuronal growth and differentiation, mainly by modulating physical properties of biological membranes and gene expression of various proteins, as well as in myelination and neurotransmission [8-11]. Therefore, a combined ID and n-3 FAD occurring early in life may exert more severe effects on brain development and functioning than an ID or n-3 FAD alone.

We have recently shown in male rats that ID and $n-3$ FAD in combination impairs monoaminergic neurotransmission and reference memory in the Morris water maze (MWM) to a greater extent than ID or n-3 FAD alone [12]. In a subsequent study we repleted doubledeficient rats with Fe and a mixture of DHA and EPA, alone and in combination, for a period of 5 weeks. We found that the repletion with either Fe or DHA/EPA alone affected monoamine pathways differently from the combined repletion and, surprisingly, even exacerbated the working memory deficits associated with double deficiency [13].

Approximately $35 \%$ of brain lipids occur in the form of polyunsaturated FA, with arachidonic acid (ARA; 20:4n-6) and DHA being the main contributors [14]. The essential n-3 FA, alpha-linolenic acid (ALA), makes up less than $1 \%$ of the brain's lipids and thus is not considered to play a direct role in brain health [15]. Indirectly, however, the intake of ALA may be crucial for brain development and functioning via its conversion to EPA and DHA. This might be particularly the case in human populations who do not consume fish and who do not have access to, or cannot afford fish oil supplements. In these populations improving DHA and EPA status by increasing the consumption of ALA-rich oils (e.g. flaxseed, canola, and soybean oils) might be a more suitable approach. However, tracer studies have shown that the rate of conversion of ALA to DHA is low in humans $(1-5 \%)$ [16-18], but has been reported to be efficient in rats $[19,20]$. A recent study in rats showed that by decreasing linoleic acid (LA; 18:2n-6) in the background diet and by keeping the total dietary polyunsaturated fatty acid (PUFA) intake low it is possible to enhance the DHA status of rats fed diets containing only ALA as a source of n-3 FA [21]. However, it is not yet known whether this finding can be extended to the human situation. Furthermore, $\mathrm{Fe}$ is a co-factor of the elongase and desaturase enzymes responsible for the conversion of ALA to EPA and DHA [17]. Several previous rodent studies have found alterations in blood and brain FA composition as a consequence of ID [22-25].

Thus, the provision of ALA in combination with Fe might be more effective in repleting brain EPA and DHA concentrations, and in reversing the deficits associated with n-3 FAD, than the provision of ALA alone, particularly in ID subjects. Therefore, the aim of this study was to investigate whether repleting double-deficient rats with ALA and Fe, alone or in combination, can correct deficits in brain monoamine metabolism and cognition associated with deficiency.

\section{Results}

Brain weight, food intake, and body weight gain

At postnatal day (PND) 92, the body weight of ID + n-3 FAD rats was significantly lower than of age-matched controls $(p<0.001)$ (Table 1$)$. Fe repletion significantly increased total body weight gain $(\mathrm{p}<0.001)$ compared to the rats receiving an ID diet and compared to controls. Furthermore, compared to the rats that received an ID diet, Fe repletion significantly increased food intake to the level of control rats. However, body weight at PND 92 remained lower in the experimental groups compared to the control group $(p<0.05$, all experimental groups vs. control).

\section{Brain Fe}

Brain Fe concentrations in all brain regions were significantly lower in the ID + n-3 FAD rats than in the agematched controls at PND $92(p<0.05)$ (Table 2). After repletion, there was a significant effect of Fe for higher Fe concentrations only in the olfactory bulb (OB). In the $\mathrm{OB}$, there was further an effect of ALA for higher Fe concentrations. The Fe + ALA group had significantly higher Fe concentrations in $\mathrm{OB}$ than the $\mathrm{Fe}+\mathrm{n}-3 \mathrm{FAD}$ $(p=0.023)$, the ID + n-3 FAD $(p=0.010)$ and the ID + ALA $(p=0.031)$ groups. The Fe concentrations in the OB of $\mathrm{Fe}+\mathrm{n}-3$ FAD and ID + n-3 FAD rats remained significantly lower than of age-matched controls. In the frontal cortex (FC), there tended to be an Fe repletion effect for higher Fe concentrations $(p=0.064)$.

\section{Brain total phospholipid fatty acids}

Repleting ID + n-3 FAD rats with ALA significantly increased the relative composition of DHA and total n-3 FA in the total phospholipid fraction of the FC, OB, striatum (Str) and hippocampus (Hip), while no effects were found on EPA (Table 2). Nonetheless, DHA and total n-3 FA composition in all four brain regions remained 
Table 1 Weight gain, food intake, and brain weight of male control rats and ID + $n-3$ FAD rats repleted with an $\mathrm{Fe}+\mathrm{ALA}, \mathrm{ID}+\mathrm{ALA}, \mathrm{Fe}+\mathrm{n}-3 \mathrm{FAD}$, or ID + n-3 FAD diet for 5 wk

\begin{tabular}{|c|c|c|c|c|c|c|c|c|}
\hline & \multirow[b]{2}{*}{ Control } & \multirow[b]{2}{*}{$\mathrm{Fe}+\mathrm{ALA}$} & \multirow[b]{2}{*}{$\mathrm{ID}+\mathrm{ALA}$} & \multirow[b]{2}{*}{$\mathrm{Fe}+\mathrm{n}-3 \mathrm{FAD}$} & \multirow[b]{2}{*}{ ID + n-3 FAD } & \multicolumn{3}{|l|}{$p$ Value } \\
\hline & & & & & & $\mathrm{Fe}$ & ALA & $\mathrm{Fe} \times \mathrm{ALA}$ \\
\hline Body weight, $g$ & $409 \pm 8.0$ & $338 \pm 12.5^{*, \Delta, *}$ & $302 \pm 7.4^{*, \#}$ & $320 \pm 7.8^{*, *}$ & $290 \pm 7.1^{*, \#, \neq}$ & 0.001 & 0.29 & 0.83 \\
\hline Total body weight gain, $g / 35 d$ & $124 \pm 4.4$ & $167 \pm 9.4^{*, \Delta, *}$ & $136 \pm 3.8^{\#, \neq}$ & $154 \pm 4.0^{*, \Delta, *}$ & $138 \pm 4.3^{\#, \neq}$ & 0.001 & 0.43 & 0.30 \\
\hline Total food intake, $\mathrm{g} / 35 \mathrm{~d}$ & $711 \pm 14.3$ & $701 \pm 26.1^{\Delta, *}$ & $624 \pm 12.1^{*, \#, \neq}$ & $666 \pm 12.2^{\Delta, *}$ & $602 \pm 9.0^{*, \#, \neq}$ & $<0.001$ & 0.14 & 0.78 \\
\hline Relative weight gain, $\mathrm{g} / \mathrm{g}$ food intake & $0.17 \pm 0.01$ & $0.24 \pm 0.01^{*, \Delta}$ & $0.22 \pm 0.01^{*, \#}$ & $0.23 \pm 0.00^{*}$ & $0.23 \pm 0.00^{*}$ & 0.20 & 0.98 & 0.14 \\
\hline
\end{tabular}

Values are means \pm SEM, $n=8-10$ per group. Abbreviations: ALA, alpha-linolenic acid; n-3 FAD, n-3 fatty acid deficient; Fe, iron; ID, iron deficient. $p$ Values correspond to two-way ANOVA to test effects of dietary Fe (deficient vs. sufficient) and dietary ALA (deficient vs. sufficient), and Fe $\times$ ALA interactions. ${ }^{*} P<0.05$ versus control group, analyzed using 1-way ANOVA with diet as between-subject variable followed by post hoc Dunnett's test to determine whether experimental (repletion) groups differed from age-matched positive-control rats after repletion with Fe and/or ALA.

${ }^{\#} P<0.05$ versus $\mathrm{Fe}+\mathrm{ALA}$ group; ${ }^{\Delta} P<0.05$ versus ID + ALA group; ${ }^{\ddagger} P<0.05$ versus Fe $+\mathrm{n}-3$ FAD group; ${ }^{¥} \mathrm{P}<0.05$ versus ID + n-3 FAD group; Analyzed using 1 -way ANOVA with diet (excluding control group) as between-subject variable followed by post hoc Tukey's test to determine differences between experimental (repletion) groups.

significantly lower than in controls in all experimental groups. In the Hip, DHA and total n-3 FA were also significantly higher in the groups receiving ALA ( $\mathrm{Fe}+\mathrm{ALA}$ and ID + ALA) compared with the Fe+n-3 FAD and the ID + n-3 FAD groups. However, there was also a significant Fe $\times$ ALA interaction, indicating that in the group receiving ALA in combination with $\mathrm{Fe}$ (Fe + ALA), the relative composition of DHA and total n-3 FA was significantly higher than in the group receiving ALA alone $(\mathrm{ID}+\mathrm{ALA})(p=0.011)$.

Table 2 Iron concentration and major phospholipid fatty acid composition in different brain regions of male control rats and ID + n-3 FAD rats repleted with an Fe + ALA, ID + ALA, Fe + n-3 FAD, or an ID + n-3 FAD diet for 5 weeks

\begin{tabular}{|c|c|c|c|c|c|c|c|c|}
\hline & \multirow[b]{2}{*}{ Control } & \multirow[b]{2}{*}{$\mathrm{Fe}+\mathrm{ALA}$} & \multirow[b]{2}{*}{ ID + ALA } & \multirow[b]{2}{*}{$\mathrm{Fe}+\mathrm{n}-3 \mathrm{FAD}$} & \multirow[b]{2}{*}{ ID + n-3 FAD } & \multicolumn{3}{|c|}{$p$ Value } \\
\hline & & & & & & $\mathrm{Fe}$ & ALA & $\mathrm{Fe} \times \mathrm{ALA}$ \\
\hline \multicolumn{9}{|c|}{ Brain $\mathrm{Fe}, \mathrm{nmol} / \mathrm{g}$ tissue } \\
\hline FC & $235 \pm 11.2$ & $210 \pm 8.8$ & $186 \pm 10.5^{*}$ & $208 \pm 10.5$ & $190 \pm 14.7^{*}$ & 0.064 & 0.97 & 0.80 \\
\hline OB & $300 \pm 21.5$ & $303 \pm 23.0^{\ddagger ; \neq, \Delta}$ & $235 \pm 9.3^{\#}$ & $234 \pm 12.1^{*, \#}$ & $222 \pm 18.7^{* \text { :\# }}$ & 0.033 & 0.009 & 0.13 \\
\hline Str & $263 \pm 13.6$ & $239 \pm 14.4$ & $223 \pm 8.0$ & $237 \pm 14.2$ & $204 \pm 17.3^{*}$ & 0.12 & 0.26 & 0.62 \\
\hline Hip & $213 \pm 6.7$ & $192 \pm 7.0$ & $186 \pm 19.8$ & $198 \pm 19.4$ & $161 \pm 11.9^{*}$ & 0.13 & 0.97 & 0.29 \\
\hline \multicolumn{9}{|c|}{ Tissue fatty acids, \% of total FA } \\
\hline \multicolumn{9}{|c|}{$20: 5$ n-3 (EPA) } \\
\hline FC & $0.05 \pm 0.01$ & $0.07 \pm 0.01$ & $0.08 \pm 0.02$ & $0.07 \pm 0.01$ & $0.05 \pm 0.01$ & 0.60 & 0.43 & 0.23 \\
\hline OB & $0.08 \pm 0.01$ & $0.10 \pm 0.02$ & $0.07 \pm 0.01$ & $0.08 \pm 0.01$ & $0.07 \pm 0.01$ & 0.10 & 0.61 & 0.32 \\
\hline Str & $0.07 \pm 0.01$ & $0.04 \pm 0.01$ & $0.07 \pm 0.01$ & $0.06 \pm 0.01$ & $0.06 \pm 0.01$ & 0.27 & 0.59 & 0.32 \\
\hline Hip & $0.20 \pm 0.10$ & $0.11 \pm 0.02$ & $0.10 \pm 0.02$ & $0.14 \pm 0.03$ & $0.09 \pm 0.03$ & 0.23 & 0.72 & 0.40 \\
\hline \multicolumn{9}{|c|}{$22: 6$ n-3 (DHA) } \\
\hline FC & $13.5 \pm 0.2$ & $7.7 \pm 0.2^{*, \neq, *}$ & $7.7 \pm 0.3^{*, \neq, *}$ & $3.7 \pm 0.1^{* * \#, \Delta}$ & $4.0 \pm 0.2^{*, \#, \Delta}$ & 0.51 & $<0.001$ & 0.53 \\
\hline OB & $16.0 \pm 0.3$ & $10.1 \pm 0.6^{* \neq, \neq, *}$ & $9.6 \pm 0.4^{*, \neq, *}$ & $4.5 \pm 0.3^{*, \#, \Delta}$ & $5.2 \pm 0.3^{*, \#, \Delta}$ & 0.75 & $<0.001$ & 0.16 \\
\hline Str & $14.1 \pm 0.3$ & $7.9 \pm 0.3^{*, \neq, \neq}$ & $7.6 \pm 0.2^{*, \ldots, \neq}$ & $4.5 \pm 0.3^{*, \#, \Delta}$ & $4.3 \pm 0.3^{*, \#, \Delta}$ & 0.34 & $<0.001$ & 0.71 \\
\hline Hip & $14.5 \pm 0.6$ & $9.7 \pm 0.6^{*, \Delta, \neq, \neq}$ & $7.7 \pm 0.2^{*, \#, \neq, \neq, *}$ & $4.2 \pm 0.3^{*, \#, \Delta}$ & $4.7 \pm 0.5^{*, \#, \Delta}$ & 0.10 & $<0.001$ & 0.007 \\
\hline \multicolumn{9}{|c|}{ Total n-3 FA } \\
\hline FC & $14.0 \pm 0.2$ & $8.4 \pm 0.3^{*, \ldots, \neq}$ & $8.6 \pm 0.3^{*, \ldots, \neq}$ & $4.0 \pm 0.2^{*, \#, \Delta}$ & $4.2 \pm 0.2^{*, \#, \Delta}$ & 0.47 & $<0.001$ & 0.92 \\
\hline OB & $16.5 \pm 0.3$ & $10.8 \pm 0.6^{*, \ldots, *}$ & $10.2 \pm 0.4^{*, \ldots, *}$ & $4.9 \pm 0.3^{*, \#, \Delta}$ & $5.6 \pm 0.3^{*, \#, \Delta}$ & 0.89 & $<0.001$ & 0.13 \\
\hline Str & $14.6 \pm 0.3$ & $8.5 \pm 0.3^{*, \neq, \neq}$ & $8.3 \pm 0.2^{*, \ldots, \neq}$ & $4.8 \pm 0.3^{*, \#, \Delta}$ & $4.7 \pm 0.3^{*, \#, \Delta}$ & 0.46 & $<0.001$ & 0.88 \\
\hline Hip & $15.5 \pm 1.0$ & $10.6 \pm 0.5^{*, \Delta, \neq, \neq}$ & $8.7 \pm 0.3^{*, \#, \neq, \neq}$ & $4.7 \pm 0.2^{*, \#, \Delta}$ & $5.2 \pm 0.5^{*, \#, \Delta}$ & 0.10 & $<0.001$ & 0.007 \\
\hline
\end{tabular}

Values are means \pm SEM, $n=8-10$ per group. Abbreviations: ALA, alpha-linolenic acid; $n-3$ FAD, $n-3$ fatty acid deficient; FC, frontal cortex; Fe, iron; Hip, hippocampus; $\mathrm{ID}$, iron deficient; $\mathrm{OB}$, olfactory bulb; Str, striatum.

$p$ Values correspond to two-way ANOVA to test effects of dietary Fe (deficient vs. sufficient) and dietary ALA (deficient vs. sufficient), and Fe $\times$ ALA interactions. ${ }^{*} P<0.05$ versus control group, analyzed using 1-way ANOVA with diet as between-subject variable followed by post hoc Dunnett's test to determine whether experimental (repletion) groups differed from age-matched positive-control rats after repletion with Fe and/or ALA.

${ }^{\#} P<0.05$ versus $\mathrm{Fe}+\mathrm{ALA}$ group; ${ }^{\Delta} P<0.05$ versus ID + ALA group; ${ }^{\ddagger} P<0.05$ versus $\mathrm{Fe}+\mathrm{n}-3 \mathrm{FAD}$ group; ${ }^{¥} \mathrm{P}<0.05$ versus ID $+\mathrm{n}-3 \mathrm{FAD}$ group; Analyzed using 1 -way ANOVA with diet (excluding control group) as between-subject variable followed by post hoc Tukey's test to determine differences between experimental (repletion) groups. 


\section{Brain monoamines}

At PND 92, dopamine (DA) concentrations concentrations (pmol/mg tissue) in the $\mathrm{FC}$ were significantly higher in the ID $+n-3$ FAD group compared with the agematched controls $(p=0.032)$, while DA concentrations of $\mathrm{Fe}+\mathrm{ALA}, \mathrm{ID}+\mathrm{ALA}$ and Fe + n-3 FAD rats did not differ from controls $(P>0.05)$ (Table 3$)$. There was a significant effect of ALA, and an Fe $\times$ ALA interaction on serotonin (5-HT) concentrations concentrations in the FC, indicating that the lowering effect of ALA in combination with Fe was attenuated when ALA was provided alone. Fe + ALA rats had significantly higher 5 -HT concentrations in the $\mathrm{FC}$ than $\mathrm{Fe}+\mathrm{n}-3 \mathrm{FAD}$ rats $(p=0.025)$. A significant $\mathrm{Fe} \times$ ALA interaction on 5-HT concentrations was also found in the $\mathrm{OB}(P<0.05)$. 5-HT concentrations in the $\mathrm{Fe}+\mathrm{n}-3$ FAD rats were significantly higher than in the ID $+n-3$
FAD $(p=0.039)$ and Fe + ALA $(p=0.049)$ rats, but this increase was attenuated when Fe was provided in combination with ALA.

\section{Morris water maze}

During the cued task of the water maze, repeatedmeasures ANOVA revealed a significant effect of trials on distance moved $(p<0.001)$ to reach the visible (cued) platform, indicative of learning over the four trials (data not shown). There was no significant effect of diet $(p=0.563)$, nor a significant diet $\times$ trial interaction $(p=0.671)$, indicating that sensory and motor deficits did not affect the groups differently. Also, diet did not affect swimming speed across trials in the cued task $(p=0.787)$. However, we did find significant differences in swimming speed between groups during the working

Table 3 Monoamine concentration (pmol/mg tissue) in three selected brain regions of male control rats and ID + $n-3$ FAD rats repleted with an Fe + ALA, ID + ALA, Fe + n-3 FAD, or an ID + n-3 FAD diet for 5 weeks

\begin{tabular}{|c|c|c|c|c|c|c|c|c|}
\hline \multirow[b]{2}{*}{ pmol/mg tissue } & \multirow[b]{2}{*}{ Control } & \multirow[b]{2}{*}{$\mathrm{Fe}+\mathrm{ALA}$} & \multirow[b]{2}{*}{ ID + ALA } & \multirow[b]{2}{*}{$\mathrm{Fe}+\mathrm{n}-3 \mathrm{FAD}$} & \multirow[b]{2}{*}{ ID + n-3 FAD } & \multicolumn{3}{|c|}{$p$ Value } \\
\hline & & & & & & $\mathrm{Fe}$ & ALA & $\mathrm{Fe} \times \mathrm{ALA}$ \\
\hline \multicolumn{9}{|l|}{$\mathrm{DA}$} \\
\hline FC & $0.19 \pm 0.06$ & $0.40 \pm 0.10$ & $0.37 \pm 0.09$ & $0.38 \pm 0.07$ & $0.55 \pm 0.10^{*}$ & 0.46 & 0.36 & 0.31 \\
\hline $\mathrm{OB}$ & $1.28 \pm 0.56$ & $0.58 \pm 0.07$ & $0.63 \pm 0.16$ & $1.02 \pm 0.21$ & $0.73 \pm 0.19$ & 0.35 & 0.09 & 0.30 \\
\hline Str & $6.87 \pm 1.58$ & $8.25 \pm 2.56$ & $9.10 \pm 2.53$ & $6.86 \pm 2.73$ & $7.68 \pm 1.58$ & 0.40 & 0.74 & 0.88 \\
\hline \multicolumn{9}{|l|}{ DOPAC } \\
\hline FC & $2.22 \pm 0.23$ & $3.03 \pm 0.50$ & $3.25 \pm 0.37$ & $2.28 \pm 0.33$ & $3.27 \pm 0.50$ & 0.13 & 0.26 & 0.31 \\
\hline $\mathrm{OB}$ & $2.99 \pm 0.44$ & $3.35 \pm 0.35$ & $2.99 \pm 0.25$ & $2.84 \pm 0.20$ & $3.51 \pm 0.36$ & 0.54 & 0.88 & 0.13 \\
\hline Str & $12.78 \pm 1.00$ & $13.55 \pm 0.87$ & $11.97 \pm 1.53$ & $13.67 \pm 2.37$ & $11.86 \pm 0.78$ & 0.64 & 0.72 & 0.53 \\
\hline \multicolumn{9}{|l|}{ HVA } \\
\hline FC & $1.04 \pm 0.12$ & $0.99 \pm 0.21$ & $1.29 \pm 0.17$ & $1.27 \pm 0.21$ & $1.26 \pm 0.22$ & 0.44 & 0.56 & 0.37 \\
\hline $\mathrm{OB}$ & $2.22 \pm 0.17$ & $1.93 \pm 0.19$ & $1.90 \pm 0.13$ & $2.12 \pm 0.10$ & $2.28 \pm 0.25$ & 0.83 & 0.11 & 0.66 \\
\hline Str & $16.26 \pm 1.24$ & $14.69 \pm 1.14$ & $14.19 \pm 1.13$ & $15.05 \pm 1.32$ & $14.42 \pm 1.00$ & 0.72 & 0.82 & 0.96 \\
\hline \multicolumn{9}{|l|}{$5-\mathrm{HT}$} \\
\hline FC & $3.30 \pm 0.66$ & $1.97 \pm 0.15^{\neq}$ & $3.93 \pm 0.74$ & $4.67 \pm 0.76^{\#}$ & $3.36 \pm 0.63$ & 0.70 & 0.031 & 0.005 \\
\hline $\mathrm{OB}$ & $2.37 \pm 0.79$ & $2.29 \pm 0.50^{\ddagger}$ & $2.76 \pm 0.60$ & $4.29 \pm 0.55^{*, *, \#}$ & $2.22 \pm 0.63^{\ddagger}$ & 0.10 & 0.34 & 0.039 \\
\hline Str & $2.58 \pm 0.66$ & $2.74 \pm 0.46$ & $2.51 \pm 0.44$ & $1.77 \pm 0.32$ & $2.34 \pm 0.52$ & 0.67 & 0.15 & 0.38 \\
\hline \multicolumn{9}{|l|}{ 5-HIAA } \\
\hline FC & $2.31 \pm 0.28$ & $2.40 \pm 0.29$ & $1.67 \pm 0.23$ & $2.28 \pm 0.31$ & $2.21 \pm 0.31$ & 0.15 & 0.46 & 0.23 \\
\hline $\mathrm{OB}$ & $2.16 \pm 0.37$ & $2.15 \pm 0.41$ & $2.54 \pm 0.21$ & $1.75 \pm 0.35$ & $1.73 \pm 0.27$ & 0.42 & 0.16 & 0.26 \\
\hline Str & $2.48 \pm 0.51$ & $7.00 \pm 1.68$ & $5.10 \pm 0.88$ & $4.09 \pm 1.21$ & $5.79 \pm 1.15$ & 0.68 & 0.30 & 0.20 \\
\hline \multicolumn{9}{|l|}{$\mathrm{NE}$} \\
\hline FC & $1.58 \pm 0.55$ & $1.92 \pm 0.42$ & $1.45 \pm 0.43$ & $2.22 \pm 0.56$ & $1.40 \pm 0.32$ & 0.14 & 0.76 & 0.78 \\
\hline $\mathrm{OB}$ & $2.77 \pm 0.80$ & $3.75 \pm 0.85$ & $2.27 \pm 0.32$ & $2.02 \pm 0.29$ & $2.35 \pm 0.40$ & 0.54 & 0.31 & 0.26 \\
\hline Str & $2.70 \pm 0.60$ & $3.16 \pm 0.55$ & $1.91 \pm 0.36$ & $3.25 \pm 0.68$ & $2.18 \pm 0.39$ & 0.05 & 0.72 & 0.71 \\
\hline
\end{tabular}

Values are means \pm SEM, $n=8-10$ per group. Abbreviations: ALA, alpha-linolenic acid; DA, dopamine; $n-3$ FAD, $n-3$ fatty acid deficient; 5 -HIAA, hydroxyindoleacetic acid; 5-HT, serotonin; DOPAC, dihydroxyphenylacetic acid; FC, frontal cortex; Fe, iron; HVA, homovanillic acid; ID, iron deficient; NE, norepinephrine; OB, olfactory bulb; Str, striatum.

$p$ Values correspond to two-way ANOVA to test effects of dietary Fe (deficient vs. sufficient) and dietary ALA (deficient vs. sufficient), and Fe $\times$ ALA interactions. ${ }^{*} P<0.05$ versus control group, analyzed using 1-way ANOVA with diet as between-subject variable followed by post hoc Dunnett's test to determine whether experimental (repletion) groups differed from age-matched positive-control rats after repletion with Fe and/or ALA.

${ }^{\#} P<0.05$ versus $\mathrm{Fe}+\mathrm{ALA}$ group; ${ }^{\ddagger} P<0.05$ versus $\mathrm{Fe}+\mathrm{n}-3 \mathrm{FAD}$ group; ${ }^{*} \mathrm{P}<0.05$ versus ID $+\mathrm{n}-3 \mathrm{FAD}$ group; Analyzed using 1 -way ANOVA with diet (excluding control group) as between-subject variable followed by post hoc Tukey's test to determine differences between experimental (repletion) groups. 
memory task. The swimming speed of Fe + ALA rats was significantly higher than of ID + ALA $(p=0.042)$ and ID + $\mathrm{n}-3 \mathrm{FAD}$ rats $(p=0.011)$. Even though not reaching significance, a similar pattern was also seen during the reference memory task. Therefore, we analyzed working memory and reference memory by using distance moved (in $\mathrm{cm}$ ) to find the hidden platform and not by escape latency (in s), which could be confounded by betweengroup differences in swimming speed.

During the working memory task, there was a significant effect of trials and days on mean distance moved (trials: $p<0.001$; days: $p<0.001$ ) to find the hidden platform (Figure 1A), indicating that overall learning and memory took place across trials and days. There was no significant effect of diet nor a diet $\times$ trial interaction. Separate $2 \times 2$ repeated-measures ANOVA to investigate the effects of Fe and ALA repletion (excluding the control group), revealed a trend towards an effect of Fe repletion for shorter distance moved to find the hidden platform in the working memory task $(p=0.061)$. Furthermore, ID + ALA rats tended to swim a longer distance to reach the hidden platform during trial 2 compared to age-matched controls $(p=0.051)$. Working memory is typically reflected in a rapid reduction of distance moved from trial 1 (when platform position is unknown) to trial 2. Therefore, we calculated the difference in distance moved between trial 1 and trial 2 across all 4 days (Figure 1B). The difference in distance moved between trial 1 and trial 2 was significantly lower in ID + ALA rats compared to age-matched controls $(p<0.05)$, indicating impaired working memory.

During the reference memory trial, there was a significant effect of days and trials, as well as a significant diet $\mathrm{x}$ trial interaction $(p=0.045)$ on distance moved, indicating that not all diet groups showed an improvement in distance moved to find the hidden platform across the 4 trials (Figure 2A). Separate analyses of the distances moved from day 1 to 4 for each diet group revealed that there was no significant improvement in distance moved from day 1 to day 4 (day: $p>0.05$ ) in the ID + ALA and Fe + n-3 FAD groups, while there was a significant improvement in the Fe + ALA ( $\mathrm{p}<0.001)$, ID + n-3 FAD $(p<0.026)$ and control $(p<0.001)$ groups. Furthermore, there was a significant effect of ALA repletion for shorter overall distance moved to find the hidden platform $(p=0.025)$ (Figure $2 \mathrm{~B})$. The Fe + ALA group, but not the ID + ALA group, swum a significantly shorter distance to find the hidden platform than the $\mathrm{Fe}+\mathrm{n}-3 \mathrm{FAD}$ $(p=0.048)$ and ID + n-3 FAD $(p=0.049)$ groups.

After 4 days of reference trials, the platform was removed and the rats were subjected to a probe trial. The percent distance the repletion groups spent in the target quadrant did not significantly differ from controls (Figure 3). However, the ID + n-3 FAD rats tended to spend a shorter distance in the target quadrant than the controls $(p=0.077)$. Only the control and ID + ALA rats showed a distinct preference for the target quadrant, indicated by percent distance spent in target quadrant being significantly above chance level (25\%) (Control, $p=0.017$; ID + ALA, $p=0.020$ ).

\section{Discussion}

This is the first study, to our knowledge, to investigate the effects of repleting male adult rats deficient in $\mathrm{Fe}$ and n-3 FA with ALA and Fe, alone and in combination, on brain monoamine concentrations and cognitive performance. The experimental model was chosen to reflect the common scenario in low-income countries where
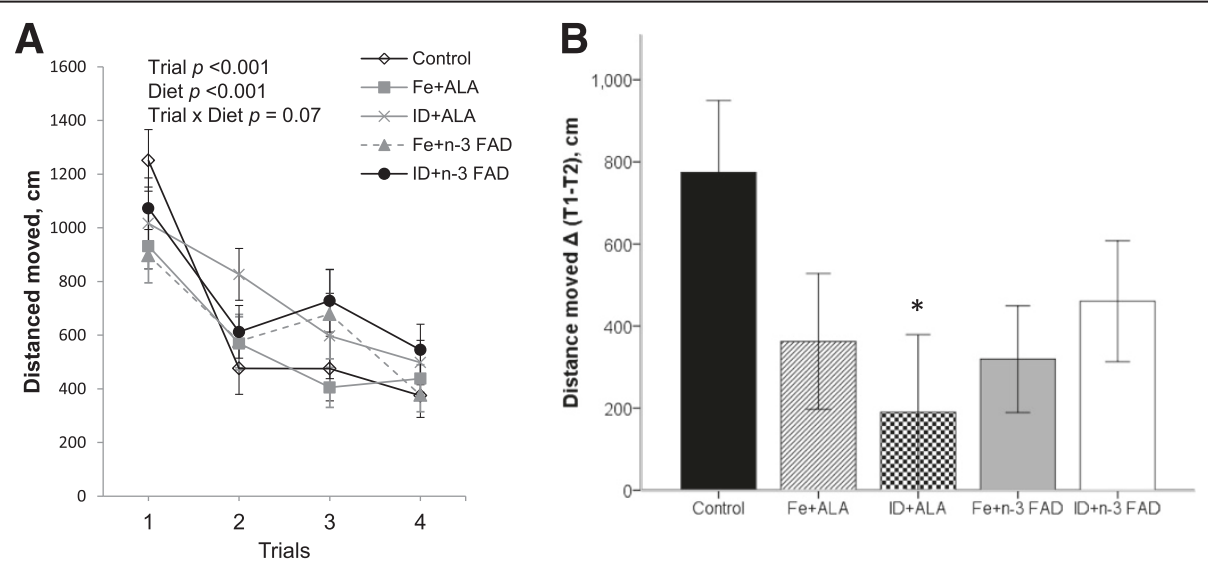

Figure 1 Working memory task in the Morris water maze (MWM). Working memory performance in the MWM of male control rats and $I D+n-3$ FAD rats repleted with an Fe + ALA, ID + ALA, Fe + n-3 FAD, or an ID + n-3 FAD diet for 5 weeks. (A) Mean distance moved per trial to reach hidden platform located at different positions across 4 days, with 4 trials per day in the working memory task; (B) working memory performance expressed as difference in distance moved between trial 1 and trial 2. Values are means \pm SEM, $n=7-8$. ALA, alpha-linolenic acid; n-3 FAD, n-3 fatty acid deficient; Fe, iron; ID, iron deficient. 

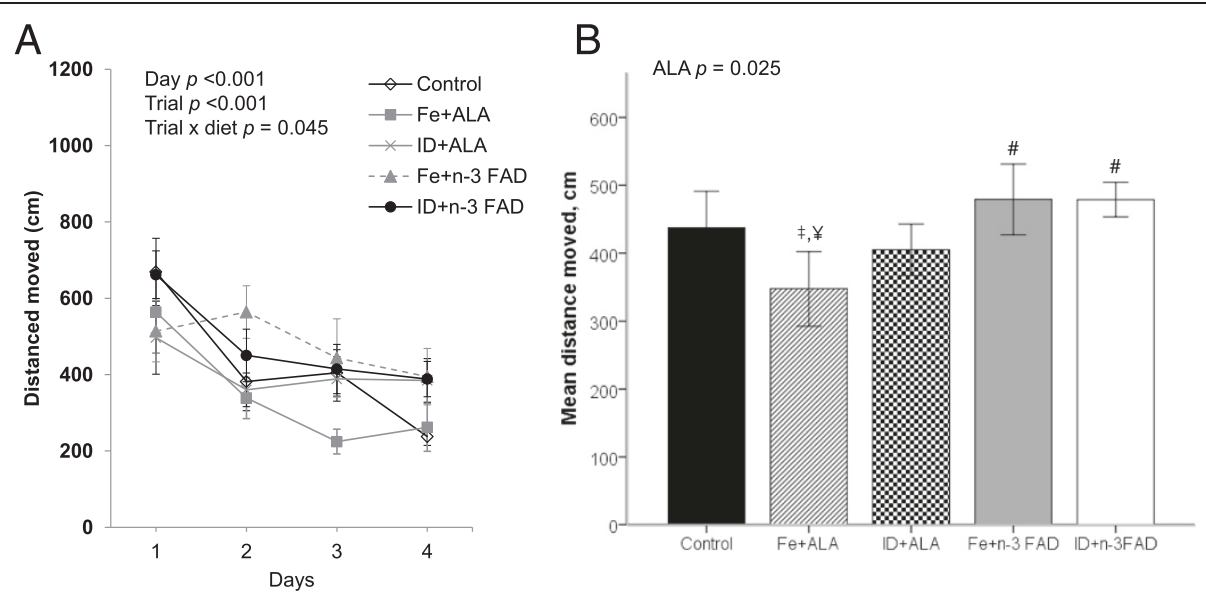

Figure 2 Reference memory task in the Morris water maze (MWM). Reference memory performance in the MWM of male control and ID + n-3 FAD rats repleted with an Fe + DHA/EPA, ID + DHA/EPA, Fe + n-3 FAD, or an ID + n-3 FAD diet for 5 weeks. (A) Mean distance moved per day to reach hidden platform located at same positions across 4 days, with 4 trials per day in the reference memory task; (B) Mean overall distance moved in the reference memory task. Values are means $\pm \mathrm{SEM}, n=7-8 .{ }^{\#} p<0.05$ versus Fe + ALA group. ${ }^{\ddagger} p<0.05$ versus Fe $+n-3$ FAD group. ${ }^{¥} \mathrm{P}<0.05$ versus ID $+\mathrm{n}-3$ FAD group. ALA, alphal-linolenic acid; $n-3$ FAD, $n-3$ fatty acid deficient; Fe, iron; ID, iron deficient.

children born to mothers with poor n-3 FA status consume a diet low in Fe and n-3 FA throughout childhood and only begin to consume a diet sufficient in one or both nutrients in early adulthood as dietary quality and variety improves.

The provision of ALA to ID + n-3 FAD rats for 5 weeks (PND 56-91) significantly increased the relative composition of DHA in total phospholipid FA of different brain regions to $\sim 50-70 \%$ of control values. In contrast, the provision of Fe resulted in near complete recovery of brain Fe ( $\sim 90-100 \%$ of controls). In the Hip, the synergistic Fe $\times$ ALA interaction for higher DHA levels may

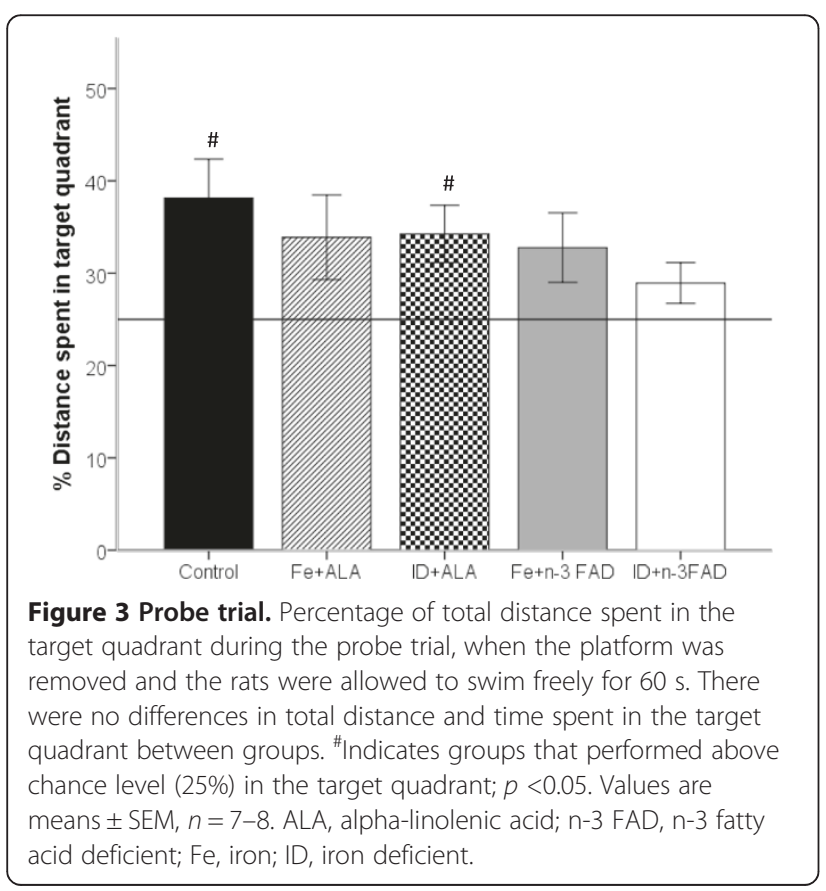

be explained by Fe being a co-factor of hepatic desaturases and elongases, which are responsible for the conversion of ALA to EPA and DHA [26,27]. Thus, providing ALA in combination with Fe to double-deficient rats might enhance the conversion of ALA into its respective long-chain derivative DHA. Whether this finding can be translated to the human situation is not clear, as previous studies have shown that, in contrast to humans, the conversion of ALA to EPA and DHA is more efficient in rats $[19,20]$. Nevertheless, Smuts et al. showed that providing ID school children with ironfortified soup not only improved Fe but also n-3 FA status [18].

Rats that remained ID during the depletion period showed a $\sim 15 \%$ reduction in food intake, which was also reflected by $\sim 15 \%$ lower body weight compared to the groups repleted with Fe. This is consistent with several previous studies reporting decreased food intake associated with poor growth in rats suffering from ID anaemia [12,28-30]. However, previous depletion studies showed that severe ID decreased relative weight gain ( $g$ weight gain per g food intake) [12,28], while in the current study, relative weight gain was the same in rats repleted with Fe and remaining ID. Since neurotransmitters, including DA and 5-HT, are involved in the regulation of food intake [31], it is possible that the reduced food intake of ID rats is related to alterations in monoaminergic neurotransmission. Also, the reduced body weight in ID rats may explain why swimming speed in the MWM was lower in ID + ALA and ID + n-3 FAD rats.

We previously showed that the provision of an ID + n-3 FAD diet for 5 weeks post-weaning resulted in an additive 1 - to 2-fold increase in DA concentrations in the $\mathrm{OB}$ and Str, and decreased 5-HT concentrations relative to 
controls in the OB at PND 56 [12]. In the current study, at PND 91, rats that remained ID + n-3 FAD had significantly higher DA concentrations than controls $(+189 \%)$ in the FC. In contrast, DA concentrations in rats that received ALA and Fe, alone or in combination, did not differ from controls, consistent with our previous study in which DHA/EPA was provided alone and in combination with Fe [13]. However, in contrast to our previous study, where we found a significant $\mathrm{Fe} \times \mathrm{DHA} / \mathrm{EPA}$ interaction on the DA metabolite dihydroxyphenylacetic acid (DOPAC) in the $\mathrm{OB}$ and Str [13], we found no Fe $\times$ ALA interactions on DOPAC in the current study. However, we did find significant antagonistic Fe $\times$ ALA interactions on 5 -HT in $\mathrm{FC}$ and $\mathrm{OB}$, which suggest that the provision of $\mathrm{Fe}$ in combination with ALA to double-deficient rats affects 5-HT concentrations differently from the provision of Fe and ALA alone. The FC is one of the last brain areas to become fully mature and previous studies have reported dramatic increases in DA- and 5-HT-mediated neurotransmission in the FC during adolescence [32-34]. This may explain why most effects of Fe and ALA repletion and of continued ID + n-3 FAD depletion at PND 91 were observed in the FC. Several rodent studies have previously investigated whether alterations in monoaminergic neurotransmission caused by ID can be reversed by Fe repletion [35-40]. These studies varied in timing and severity of ID, in timing and dose of iron repletion, as well as in the brain regions observed. Generally, the effects of ID induced during gestation and pre-weaning have been shown to be persistent $[35,36,39,40]$. Rodent studies using a model of post-weaning ID are limited. To our knowledge, to date, only one study has shown that alterations in extracellular DA in the caudate putamen caused by ID introduced post-weaning were mostly reversible by iron repletion [41]. Also, few studies have investigated whether the detrimental effects of n-3 FAD (induced over two generations) on monoaminergic neurotransmission can be reversed with ALA repletion [42,43]. Kodas et al. investigated synaptic levels of DA and 5-HT in basal conditions and after pharmacological stimulation in rats that were n-3 FA depleted and in rats that were repleted with an ALA sufficient diet starting at different time points (birth, PND 7, PND 14 or PND 21) [42,43]. N-3 FA deficiency altered DA and 5-HT release in basal conditions and under stimulation in the rat Hip. The provision of ALA during the first two weeks of postnatal life reversed these alterations, while they persisted in rats that received the repletion diet only from PND 21.

Nonetheless, our results cannot be directly compared with the results of these studies, as the experimental rats in our study were deficient in both Fe and n-3 FA before receiving the repletion diets. Thus, the effects of Fe or n-3 FA repletion could have been confounded by the untreated deficiency. It is well known that neurotransmitter systems can adapt to chronic stressors, such as drug and alcohol exposure [44]. This could explain why certain monoamines that were altered in the ID $+n-3$ FAD rats after the depletion study (PND 56) were no longer altered in the rats that remained ID + n-3 FAD during the repletion study (at PND 92). We speculate that providing double-deficient rats with one nutrient only affects the adapted system differently than the provision of both nutrients, e.g. by re-activating different mechanisms, which may explain the different effects on brain 5-HT concentrations when $\mathrm{Fe}$ and ALA were provided alone and in combination.

Disturbances in DA and 5-HT neurotransmission can impair learning and memory [45]. The results from the MWM testing indicate that the provision of ALA alone to double-deficient rats significantly impairs working memory performance compared to age-matched controls. This finding is consistent with our previous study, where the provision of DHA/EPA alone also produced significant deficits in working memory performance compared to age-matched controls [13]. The mechanism of this effect is uncertain. Spatial working memory is mainly hippocampal-dependent but is sub-served in part by the prefrontal cortex $[45,46]$. Therefore, the working memory results might be explained by the differential effects of ALA on 5-HT in the FC when provided alone and in combination with Fe. There is evidence suggesting that 5-HT is involved in working and reference memory processes $[45,47]$. Unfortunately, data on monoamine concentrations in the Hip are not available in the current study.

We consistently demonstrated that rats repleted with ALA or Fe alone showed no learning effect in the reference memory task, indicated by a lack of improvement in distance swum across trials and days to find the hidden platform. On the other hand, rats that received ALA in combination with $\mathrm{Fe}$ exhibited a marked improvement. This finding could again be attributed to the differential effects of ALA and Fe on 5-HT concentrations in the FC when provided alone or in combination. Consistently, a recent study reported that ID rats fed with Fe and a mixture of essential FA, containing equal amounts of LA and ALA, exhibited improved learning and memory performance in the MWM compared with controls, while the rats fed with Fe alone performed worse [48]. In contrast to our previous study that provided DHA/ EPA, alone and in combination [13], we did find that the provision of ALA significantly shortened overall distance moved to find the hidden platform during the reference memory task. However, this beneficial effect of ALA was only apparent in the Fe + ALA group, which swam a significantly shorter distance to find the platform than the groups that remained double-deficient or received Fe or ALA only. Since spatial learning and memory tested in the MWM is mainly hippocampus-dependent $[49,50]$, 
the higher relative composition of DHA in total phospholipid FA in the Hip of rats that were fed ALA in combination with Fe might explain the improved reverence memory performance in this group. Nevertheless, it may be that ALA exerted beneficial effects on cognitive performance independent of its conversion to EPA and DHA.

Since spatial working and reference memory is mainly hippocampal-dependent, it is a limitation of this study that monoamine concentrations were not analyzed in the Hip. Also, the assessment of other neurotransmitters, such as glutamate and gamma-aminobutyric acid, or other factors involved in learning and behaviour, such as myelination, neuronal inflammation, and processes of morphogenesis and cell growth, would have been valuable.

\section{Conclusion}

Consistent with our previous study in which a mixture of DHA/EPA was provided, alone and in combination with Fe, feeding either ALA or Fe alone to adult rats with both ID and n-3 FAD affected brain 5-HT concentrations differently from the provision of ALA and Fe in combination, and even exacerbated the working memory deficits associated with combined deficiency. However, in contrast to our previous study, the provision of ALA had a beneficial effect on reference memory, particularly when provided in combination with $\mathrm{Fe}$, which may be explained by the enhancing effect of $\mathrm{Fe}$ on the conversion of ALA to DHA in the Hip. These findings are of relevance to human populations, as many children from a low-socioeconomic background may suffer from both ID and n-3 FAD due to poor quality diets. Furthermore, in populations with a low fish intake, improving DHA and EPA status by increasing the consumption of ALArich oils (e.g. flaxseed, canola or soybean oils) might be a more suitable approach. Our results indicate that in such populations, it may be crucial to provide ALA-rich oils and foods in combination with Fe.

\section{Methods}

\section{Rats and diets}

All experimental procedures were approved by the Veterinary Office of the Department of Health of the Canton of Zürich. Male Wistar rats were first made n-3 FAD over two generations. Male rats were chosen to avoid potential confounding effects of estrogen that have been reported in previous studies of ID and n-3 FAD [51,52]. At a commercial animal breeder (RCC), female Wistar rats (PND 21) were fed an n-3 FAD diet (detailed below), and were mated at 11 weeks with 12-week-old male breeders of the same strain. After the mating period, the females continued to consume the n-3 FAD diet and the rat pups were kept with their dams until weaning. After weaning at PND 21, male n-3 FAD rats received a concurrent ID and n-3 FAD (ID + n-3 FAD) diet for a depletion period of 5 weeks. At PND 56, the now ID $+n-3$ FAD rats $(n=39)$ were randomly divided into four groups (Figure 4). The repletion study was designed as a $2 \times 2$ factorial experiment and the four groups received the following diets for a period of $5 \mathrm{wk}: 1)$ a continued ID and $\mathrm{n}-3$ FAD (ID + n-3 FAD, $n=10) ; 2)$ Fe replete and n-3 FAD

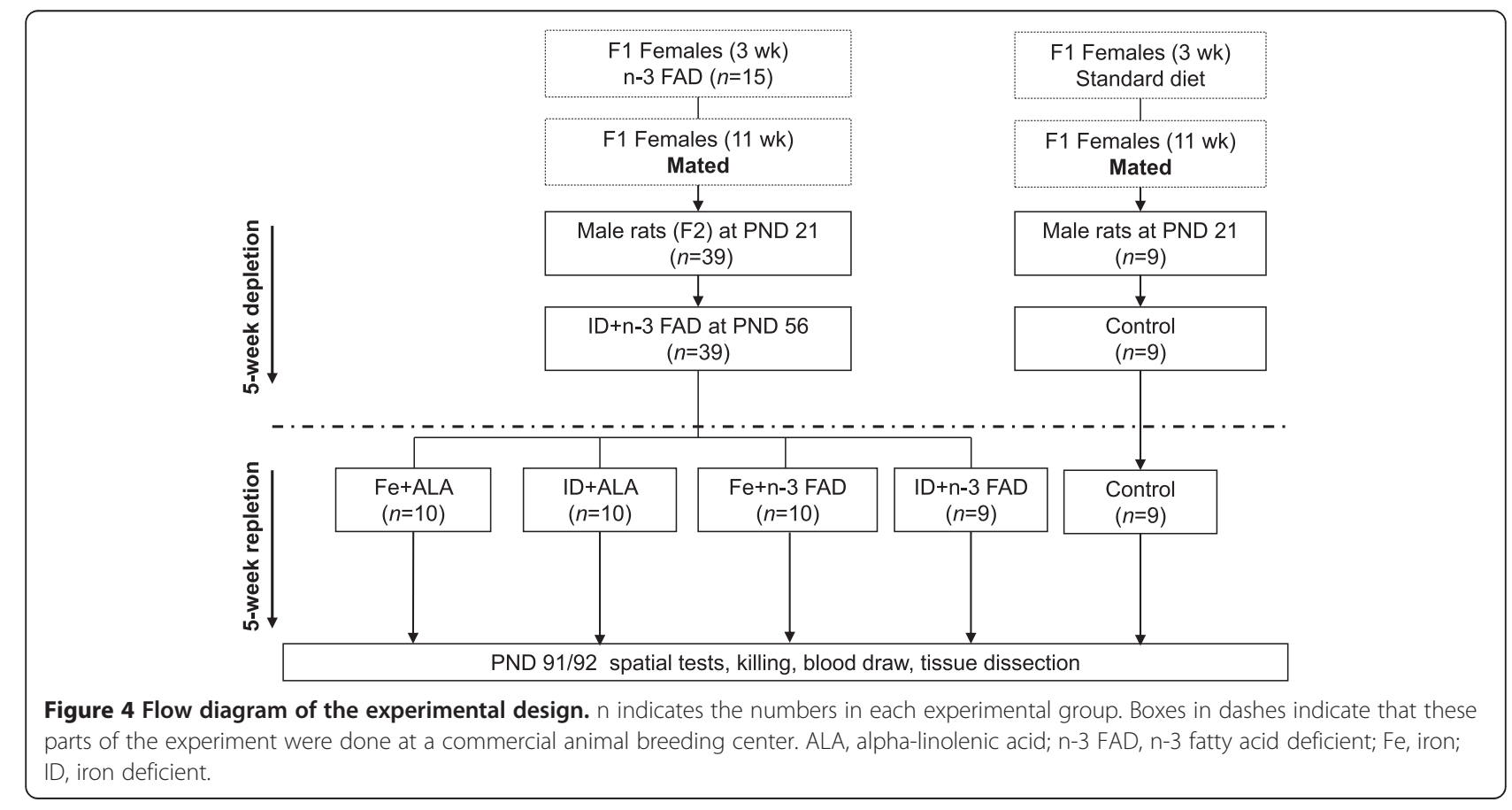


$(\mathrm{Fe}+\mathrm{n}-3 \mathrm{FAD}, n=10) ; 3) \mathrm{Fe}$ and ALA replete $(\mathrm{Fe}+\mathrm{ALA}$, $n=10)$; or 4) ID and ALA replete (ID + ALA, $n=10)$ diet. Furthermore, we included an age-matched (positive-) control group from dams that received the n-3 FA and Fe sufficient basal AIN-93G diet.

The purified experimental diets were obtained commercially (Dyets, Bethlehem, PA, USA) and were based on the AIN-93G [53] formulation with modifications in Fe content and fat source (Table 4). All diets contained $10 \%$ fat. The n-3 FAD diets contained hydrogenated coconut oil at $81 \mathrm{~g} / \mathrm{kg}$ diet, and safflower oil at $19 \mathrm{~g} / \mathrm{kg}$ diet. The ALA repletion diets contained hydrogenated coconut oil at $60 \mathrm{~g} / \mathrm{kg}$ diet, safflower oil at $32 \mathrm{~g} / \mathrm{kg}$ diet and flaxseed oil at $8 \mathrm{~g} / \mathrm{kg}$ diet. All diets included n-6 FA in the form of LA. The Fe replete diets contained $35 \mathrm{mg}$ $\mathrm{Fe} / \mathrm{kg}$, and the ID diets during the preceding depletion period of 5 weeks contained $3 \mathrm{mg} \mathrm{Fe} / \mathrm{kg}$. For the repletion period, the Fe dose in the ID diets was increased to $10 \mathrm{mg} \mathrm{Fe} / \mathrm{kg}$ diet in order to avoid potential deaths from prolonged severe ID anemia. All diets were custom prepared in powdered form to avoid lipid oxidation during pelletization, vacuum packed in bags of $2 \mathrm{~kg}$, and stored at $-20^{\circ} \mathrm{C}$ until use.

Table 4 Composition of experimental diets during depletion period $^{*}$

\begin{tabular}{|c|c|c|c|}
\hline Ingredient & \multicolumn{3}{|c|}{ g/kg diet } \\
\hline Casein, vitamin free & \multicolumn{3}{|c|}{200} \\
\hline Carbohydrate & \multicolumn{3}{|c|}{600} \\
\hline Cornstarch & \multicolumn{3}{|c|}{368} \\
\hline Sucrose & \multicolumn{3}{|c|}{100} \\
\hline Deytrose & \multicolumn{3}{|c|}{132} \\
\hline Cellulose & \multicolumn{3}{|c|}{50} \\
\hline Mineral mix ${ }^{\#}$ & \multicolumn{3}{|c|}{35} \\
\hline Vitamin mix & \multicolumn{3}{|c|}{10} \\
\hline L-Cystein & \multicolumn{3}{|c|}{3} \\
\hline Choline bitartrate & \multicolumn{3}{|c|}{2.5} \\
\hline $\mathrm{TBHQ}$ & \multicolumn{3}{|c|}{0.02} \\
\hline \multirow[t]{2}{*}{ Fat } & \multicolumn{3}{|c|}{100} \\
\hline & $n-3$ FAD $^{\dagger}$ & ALA sufficient $^{\ddagger}$ & Control $^{\ddagger}$ \\
\hline Coconut oil (hydrogenated) & 81.0 & 60.0 & 30.0 \\
\hline Soybean oil & 0.0 & 0.0 & 70.0 \\
\hline Safflower oil & 19.0 & 32.0 & 0.0 \\
\hline Flaxseed oil & 0.0 & 8.0 & 0.0 \\
\hline \multicolumn{4}{|c|}{ 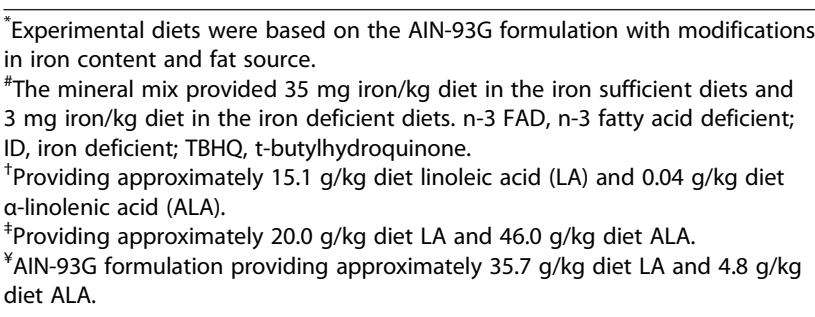 } \\
\hline
\end{tabular}

\section{Tissue collection}

At the end of the repletion period (PND 91 and 92) rats were exposed to $\mathrm{CO}_{2}$ to introduce unconsciousness for blood collection by cardiac puncture and then killed by decapitation. The brains were rapidly removed and $\mathrm{OB}$, FC, Str and Hip were isolated from both hemispheres by freehand dissection. Brain regions were placed into preweighed Eppendorf tubes, their wet weight was recorded and then they were snap-frozen in liquid nitrogen and stored at $-80^{\circ} \mathrm{C}$. Per brain area, tissues obtained from the left and right hemispheres were alternately used for the analysis of brain iron and FA content.

\section{Brain iron analysis}

Brain regions were homogenized and digested with nitric acid according to Erikson et al. [54], and total Fe concentrations measured using graphite furnace atomic absorption spectrometry (AAS; Perkin Elmer AA400, Beaconsfield, Bucks, UK) as described previously [12].

\section{Total phospholipid fatty acid analysis}

Lipids were extracted from each brain region with chloroform:methanol $(2: 1 \mathrm{v} / \mathrm{v})$ by a modification of the method of Folch et al. [55]. The lipid extracts were concentrated and the neutral lipids separated from the phospholipids by thin-layer chromatography (TLC) (Silica gel 60 plates, $10 \times 20 \mathrm{~cm}$, Merck, Darmstadt, Germany) and eluted with diethyl ether: petroleum ether: acetic acid (30:90:1 v/v/v). The lipid band containing phospholipids was removed from the TLC plate and transmethylated with methanol:sulphuric acid $(95: 5 \mathrm{v} / \mathrm{v})$ at $70^{\circ} \mathrm{C}$ for $2 \mathrm{~h}$ to yield fatty acid methyl esters (FAME). The resulting FAME was extracted with water and hexane. The organic layer was evaporated, re-dissolved in hexane and analyzed by QP GC-EI-MS on an Agilent Technologies 7890A GC system equipped with an Agilent Technologies 5975C VL mass selective detector. The GC separation of FAME was carried out on an HB-5MS capillary column (30 m $\times$ $0.250 \mathrm{~mm} \times 0.25 \mu \mathrm{m}$; Agilent $\mathrm{J} \& \mathrm{~W})$ using helium as the carrier gas at a flow rate of $0.9 \mathrm{~mL} / \mathrm{min}$. The $\mathrm{GC}$ injector was held at a temperature of $250^{\circ} \mathrm{C}$ and the MS source and QP were maintained at temperatures of $230^{\circ} \mathrm{C}$ and $150^{\circ} \mathrm{C}$ respectively. The injection volume of the sample solution was $1 \mu \mathrm{L}$, using a split ratio of 1:25 for the brain samples. The oven temperature started at $140^{\circ} \mathrm{C}$ and was programmed at $+3^{\circ} \mathrm{C} / \mathrm{min}$ from 140 to $220^{\circ} \mathrm{C}$, held at $220^{\circ} \mathrm{C}$ for $2 \mathrm{~min}$, then programmed at $+3^{\circ} \mathrm{C} / \mathrm{min}$ to $230^{\circ} \mathrm{C}$ and held at $230^{\circ} \mathrm{C}$ for $10 \mathrm{~min}$. Total analysis time was $45 \mathrm{~min}$. Mass spectrometry with $70 \mathrm{eV}$ EI was carried out in full scan acquisition mode and all mass spectra were acquired over the $\mathrm{m} / \mathrm{z}$ range of 50-750. Quantification of FAME was done using the selected ion extraction (SIE) method. 
For the calibration of FAME, a standard reference mixture of 26 FAME (Nu-Check-Prep, Elysian, MN) and three single FAME standards (Larodan Fine Chemicals $\mathrm{AB}$, Malmö, SE) were injected at equal concentrations ranging between 1 and $400 \mathrm{ng}$ in $1 \mu \mathrm{L}$ and calibration plots for each FAME were obtained using peak areas from mass chromatograms, using $\mathrm{C} 17: 0$ as an external standard. Data analysis was performed using MSD Chem Station software (Agilent G1701EA version E.02.00.493). Relative percentages of FA were calculated by taking the concentration of a given FA derivative as a percentage of the total concentration of all FA identified in the sample.

\section{Brain monoamine analysis}

DA dihydroxyphenylacetic acid (DOPAC), homovanillic acid (HVA), 5-HT, 5-hydroxyindoleacetic acid (5-HIAA) and norepinephrine (NE) were measured in Str, FC and $\mathrm{OB}$ using reverse-phase HPLC with electrochemical detection. Several previous rodent studies have shown that monoaminergic neurotransmission in these brain regions was affected by ID and/or n-3 FAD [35,36,43,56-58]. We initially also planned to measure monoamine concentrations in the Hip. However, unfortunately the Hip samples got lost during shipment to the analytical laboratory. The regions were prepared and analyzed as described elsewhere with minimal modifications [7,41]. Briefly, $1 \mathrm{~g}$ of tissue was diluted into $10 \mathrm{~mL}$ PBS spiked with complete protease inhibitor tablets (Roche Diagnostics, Mannheim, Germany). Samples were homogenized on ice with a PT 1200 E Polytron tissue homogenizer using acid washed plastic dispersing-aggregates (single use; Kinematic AG, Littau, Switzerland). Homogenates were then passed 10 times through a $1 \mathrm{~mL}$ insulin syringe with $29 \mathrm{G} \times 12.7 \mathrm{~mm}$ needle (Beckton Dickinson AG, Allschwil, Switzerland) to further homogenize the tissue. Homogenates were sonicated with 5 up and down strokes. $50 \mu \mathrm{L}$ of the homogenate were added to $50 \mu \mathrm{L} 0.24 \mathrm{M} \mathrm{HClO} 4.10 \mu \mathrm{L}$ internal standard (dihydroxybenzylamine, $1.1 \mathrm{mg} / \mathrm{L}$ ) was added to track efficiency of extraction in all samples. The spiked solution was sonicated for $10 \mathrm{~s}$, filtered using Costar Spin-X filter tubes $0.2 \mu \mathrm{m}$ (Corning, NY, USA), and $10 \mu \mathrm{L}$ was injected onto the HPLC by an ESA 542 refrigerated auto sampler, as described by Bianco et al. [7].

\section{Morris water maze test}

The MWM was used to evaluate spatial learning and memory performance. The MWM test was carried out in the dark phase of the cycle in eight randomly selected rats from the experimental groups and from the control group. The maze consisted of a black, circular, fiberglass tank ( $2 \mathrm{~m}$ in diameter) that was positioned in the middle of a testing room enriched with unique distal spatial cues under dim lighting condition (12 lux as measured from the maze centre). The tank was filled daily with fresh tap water $\left(22 \pm 1^{\circ} \mathrm{C}\right)$ to a depth of $30 \mathrm{~cm}$. A black, circular platform $(11 \mathrm{~cm}$ in diameter) submerged $1.5 \mathrm{~cm}$ below the water surface was used as an escape platform invisible to the rats. All trials were monitored by a video camera installed above the water maze, and analyzed using Ethovision software version 3.1 (Noldus).

The rats underwent four phases of testing in the water maze on 10 consecutive days: 1) Cued task (1 d, PND $80)$; 2) Working memory task (4 d, PND 81-84); 3) Reference memory task (4 d, PND 85-88) and; 4) Probe test (1 d, PND 89).

First, the rats were familiarized to the water maze procedure in a cued task, which also served as a test for nonspecific sensory motor differences. In this pre-training phase, the platform was positioned in the center of the maze and was made visible with a local cue (flag). Each rat underwent 4 consecutive trials, with the starting position randomly selected from four release points $(\mathrm{N}, \mathrm{W}, \mathrm{S}$, and E). Each rat was released into the water facing the outer edge of the pool and was allowed a maximum of $90 \mathrm{~s}$ to escape onto the platform. If a rat failed to do so, a maximum escape latency of $60 \mathrm{~s}$ was recorded, and the rat was guided to the platform by the experimenter and allowed to stay on it for an inter-trial interval of $15 \mathrm{~s}$ before the next trial.

The next day, in the working memory task, the platform position (randomized across rats) varied from one day to the next in a non-repetitive manner, but remained submerged, but without the local cue, at the same position across the four trials within a day. The four platform positions were $16 \mathrm{~cm}$ off the wall in the NW, NE, SE and SW directions of the tank. The starting positions varied randomly across the trials amongst the four possible release points $(\mathrm{N}, \mathrm{W}, \mathrm{S}$ and $\mathrm{E})$. The rats were allowed $90 \mathrm{~s}$ to find the platform and the inter-trial interval was $15 \mathrm{~s}$. This task taxes the flexible use of day-dependent short-term (working) memory [59]. As previously, when a rat failed to locate the platform within $90 \mathrm{~s}$, it was guided to it and a maximum escape latency of $60 \mathrm{~s}$ was recorded.

The reference memory task began the day after completion of the working memory task. This task assessed long-term spatial memory, by applying a procedure in which the platform remained in a constant location across trials ( 4 trials per day) and across training days (4 days), while the starting positions changed randomly across trials. As described above, the rats were allowed to search for the platform for $90 \mathrm{~s}$, with an inter-trial interval of $15 \mathrm{~s}$.

A probe test was conducted $24 \mathrm{~h}$ after the final reference trial to assess memory retention. To this end, the platform was removed from the tank and the rats were released in the quadrant opposite to the trained platform 
location. The rats were allowed to swim freely in the water maze for $60 \mathrm{~s}$ (one trial only). The distance covered in each quadrant was recorded.

After each training day in the water maze, the rats were dried under a red-light heat lamp, before being returned to their home cages.

\section{Statistical analysis}

Data were analyzed using IBM SPSS Statistics software (version 20.0). Data were examined for normality of distribution by a Shapiro-Wilk test and the presence of outliers ( \pm 3 SD from the mean, boxplots). Homogeneity of variance was examined by Levene's test. Datasets that significantly deviated from normality and/or variance homogeneity were transformed prior to interferential statistical analysis using ANOVA.

This repletion study was designed as a $2 \times 2$ factorial experiment. Figure 1 shows that the control group did not have the same dietary history as the repletion groups. The control group was used as a positive-control to examine whether repletion with either nutrient alone or in combination can reverse deficits in cognition and changes in biochemical indicators associated with doubledeficiency to a level of age-matched rats that received an n-3 FA and Fe sufficient basal AIN-93G diet throughout their lives. Therefore, we performed two different statistical analyses with the following aims: 1) 2-way ANOVA for biochemical indicators and 2-way repeated measures ANOVA (with trials and days as repeated measurement variables) for MWM data, excluding the control group, to determine the effects of $\mathrm{Fe}$ (sufficient vs. deficient) and ALA (sufficient vs. deficient) repletion and their interactions in double-deficient rats. Tukey's tests (Fisher's least significant difference tests for MWM data) were used for appropriate pair-wise comparison following the emergence of significant effects from the overall ANOVA. Significant treatment effects in the absence of a significant interaction effect indicated additive effects of the treatments, whereas a significant interaction implied synergism or antagonism; 2) 1-way ANOVA with diet as betweensubject variable followed by post hoc Dunnett's test to determine whether experimental (repletion) groups differed from age-matched positive-control rats after repletion with Fe and/or ALA.

For the MWM probe trial, the percentage distance and time spent in the target quadrant were compared between groups using 1-way ANOVA with diet as between-subject variable followed by Fisher's least significant difference tests. Furthermore, one-sample t-tests were carried out to investigate whether distance moved in the target quadrant was above the chance level of $25 \%$. The results were expressed as means \pm SEM and differences were considered significant at $p<0.05$.

\section{Abbreviations}

ALA: Alpha-linolenic acid; ARA: Arachidonic acid; DA: Dopamine; DHA: Docosahexaenoic acid; DOPAC: Dihydroxyphenylacetic acid; EPA: Eicosapentaenoic acid; n-3 FA: n-3 fatty acids; n-3 FAD: n-3 fatty acid deficiency; FAME: Fatty acid methyl ester; FC: Frontal cortex; Fe: Iron; 5-HIAA: 5-hydroxyindoleacetic acid; Hip: Hippocampus; 5-HT: Serotonin; ID: iron deficiency; LA: Linoleic acid; MWM: Morris water maze; OB: Olfactory bulb; PND: Postnatal day; PUFA: Polyunsaturated fatty acid; Str: Striatum; TLC: Thin-layer chromatography.

\section{Competing interests}

The authors declare that they have no competing interests.

\section{Authors' contributions}

The authors' responsibilities were as follows: MBZ, CMS and JB designed research; JB conducted research; JB analyzed data; JB prepared the first draft of the paper that was revised by CMS and MBZ, and JB had primary responsibility for final content. All authors read and approved the final manuscript.

\section{Acknowledgements}

We thank Caroline Remijn (Unilever R \& D, Vlaardingen, The Netherlands) for conducting the brain iron analysis, Laura E Bianco (Department of Nutrition Sciences, The Pennsylvania State University, USA) for conducting the monoamine analyses in the different brain regions, Myrtha Arnold and Wolfgang Langhans (Laboratory of Physiology and Behaviour, ETH Zürich, Switzerland) for technical assistance in conducting the animal study, and Benjamin K Yee (Legacy Research Institute, Portland, USA) for assistance in analyzing and interpreting the Morris Water Maze data. Financial support for the study was provided by Unilever Research and Development, Vlaardingen the Netherlands; and the Swiss Foundation for Nutrition Research (SFEFS).

Received: 4 March 2014 Accepted: 2 June 2014

Published: 13 June 2014

\section{References}

1. Briend A, Dewey KG, Reinhart GA: Fatty acid status in early life in low-income countries-overview of the situation, policy and research priorities. Matern Child Nutr 2011, 7(Suppl 2):141-148.

2. Stoltzfus RJ: Iron interventions for women and children in low-income countries. J Nutr 2011, 141:756S-762S.

3. Connor JR, Menzies SL: Relationship of iron to oligodendrocytes and myelination. Glia 1996, 17:83-93.

4. Beard JL, Connor JR: Iron status and neural functioning. Annu Rev Nutr 2003, 23:41-58.

5. LeBlanc $C P$, Fiset $S$, Surette $M E$, O'Brien $H T$, Rioux FM: Maternal iron deficiency alters essential fatty acid and eicosanoid metabolism and increases locomotion in adult Guinea pig offspring. J Nutr 2009, 139:1653-1659.

6. Todorich B, Pasquini JM, Garcia Cl, Paez PM, Connor JR: Oligodendrocytes and Myelination: the role of iron. Glia 2009, 57:467-478.

7. Bianco LE, Wiesinger J, Earley $C J$, Jones BC, Beard JL: Iron deficiency alters dopamine uptake and response to L-DOPA injection in Sprague-Dawley rats. J Neurochem 2008, 106:205-215.

8. Uauy R, Dangour AD: Nutrition in brain development and aging: role of essential fatty acids. Nutr Rev 2006, 64:S24-33. discussion S72-91.

9. Salvati S, Natali F, Attorri L, Di Benedetto R, Leonardi F, Di Biase A, Ferri F, Fortuna S, Lorenzini P, Sanchez M, Ricceri L, Vitelli L: Eicosapentaenoic acid stimulates the expression of myelin proteins in rat brain. J Neurosci Res 2008, 86:776-784.

10. Calder PC, Grimble RF: Polyunsaturated fatty acids, inflammation and immunity. Eur J Clin Nutr 2002, 56(Suppl 3):S14-19.

11. Schuchardt JP, Huss M, Stauss-Grabo M, Hahn A: Significance of long-chain polyunsaturated fatty acids (PUFAs) for the development and behaviour of children. Eur J Pediatr 2010, 169:149-164.

12. Baumgartner J, Smuts CM, Malan L, Arnold M, Yee BK, Bianco LE, Boekschoten MV, Muller M, Langhans W, Hurrell RF, Zimmermann MB: Combined deficiency of iron and $(n-3)$ fatty acids in male rats disrupts brain monoamine metabolism and produces greater memory deficits than iron deficiency or (n-3) fatty acid deficiency alone. J Nutr 2012, 142:1463-1471. 
13. Baumgartner J, Smuts CM, Malan L, Arnold M, Yee BK, Bianco LE, Boekschoten MV, Muller M, Langhans W, Hurrell RF, Zimmermann MB: In male rats with concurrent iron and ( $n-3)$ fatty acid deficiency, provision of either iron or ( $n-3)$ fatty acids alone alters monoamine metabolism and exacerbates the cognitive deficits associated with combined deficiency. J Nutr 2012, 142:1472-1478.

14. McNamara RK, Carlson SE: Role of omega-3 fatty acids in brain development and function: potential implications for the pathogenesis and prevention of psychopathology. Prostaglandins Leukot Essent Fatty Acids 2006, 75:329-349.

15. Innis SM: Plasma and red blood cell fatty acid values as indexes of essential fatty acids in the developing organs of infants fed with milk or formulas. J Pediatr 1992, 120:S78-86.

16. Arterburn $L M$, Hall EB, Oken $H$ : Distribution, interconversion, and dose response of n-3 fatty acids in humans. Am J Clin Nutr 2006, 83:1467S-1476S.

17. Plourde M, Cunnane SC: Extremely limited synthesis of long chain polyunsaturates in adults: implications for their dietary essentiality and use as supplements. Appl Physiol Nutr Metab 2007, 32:619-634.

18. Burdge GC, Calder PC: Conversion of alpha-linolenic acid to longer-chain polyunsaturated fatty acids in human adults. Reprod Nutr Dev 2005, 45:581-597.

19. Rapoport SI, Igarashi M: Can the rat liver maintain normal brain DHA metabolism in the absence of dietary DHA? Prostaglandins Leukot Essent Fatty Acids 2009, 81:119-123.

20. Gao F, Kiesewetter D, Chang L, Ma K, Bell JM, Rapoport SI, Igarashi M: Whole-body synthesis-secretion rates of long-chain n-3 PUFAs from circulating unesterified alpha-linolenic acid in unanesthetized rats. J Lipid Res 2009, 50:749-758.

21. Gibson RA, Neumann MA, Lien EL, Boyd KA, Tu WC: Docosahexaenoic acid synthesis from alpha-linolenic acid is inhibited by diets high in polyunsaturated fatty acids. Prostaglandins Leukot Essent Fatty Acids 2013, 88:139-146.

22. Cunnane SC, McAdoo KR: Iron intake influences essential fatty acid and lipid composition of rat plasma and erythrocytes. J Nutr 1987, 117:1514-1519.

23. Stangl Gl, Kirchgessner M: Different degrees of moderate iron deficiency modulate lipid metabolism of rats. Lipids 1998, 33:889-895.

24. Leblanc CP, Surette ME, Fiset S, Turgeon O'Brien H, Rioux FM: Maternal iron deficiency and its effect on essential fatty acid and eicosanoid metabolism and spatial memory in the guinea pig offspring. Prostaglandins Leukot Essent Fatty Acids 2009, 81:1-8.

25. Tichelaar HY, Smuts CM, Gross R, Jooste PL, Faber M, Benade AJ: The effect of dietary iron deficiency on the fatty acid composition of plasma and erythrocyte membrane phospholipids in the rat. Prostaglandins Leukot Essent Fatty Acids 1997, 56:229-233.

26. Tocher DR, Leaver MJ, Hodgson PA: Recent advances in the biochemistry and molecular biology of fatty acyl desaturases. Prog Lipid Res 1998, 37:73-117.

27. Nakamura MT, Nara TY: Structure, function, and dietary regulation of delta6, delta5, and delta9 desaturases. Annu Rev Nutr 2004, 24:345-376.

28. Beard JL, Zhan CS, Brigham DE: Growth in iron-deficient rats. Proc Soc Exp Biol Med 1995, 209:65-72.

29. Unger EL, Bianco LE, Burhans MS, Jones BC, Beard JL: Acoustic startle response is disrupted in iron-deficient rats. Pharmacol Biochem Behav 2006, 84:378-384.

30. Pinero $D$, Jones $B$, Beard J: Variations in dietary iron alter behavior in developing rats. J Nutr 2001, 131:311-318.

31. Volkow ND, Wang GJ, Baler RD: Reward, dopamine and the control of food intake: implications for obesity. Trends Cogn Sci 2011, 15:37-46.

32. Anderson V, Catroppa C, Morse S, Haritou F, Rosenfeld J: Recovery of intellectual ability following traumatic brain injury in childhood: impact of injury severity and age at injury. Pediatr Neurosurg 2000, 32:282-290

33. Spear LP: The adolescent brain and age-related behavioral manifestations. Neurosci Biobehav Rev 2000, 24:417-463.

34. Thatcher RW: Maturation of the human frontal lobes - physiological evidence for staging. Dev Neuropsychol 1991, 7:397-419.

35. Unger EL, Paul T, Murray-Kolb LE, Felt B, Jones BC, Beard JL: Early iron deficiency alters sensorimotor development and brain monoamines in rats. J Nutr 2007, 137:118-124.
36. Unger EL, Hurst AR, Georgieff MK, Schallert T, Rao R, Connor JR, Kaciroti N, Lozoff B, Felt B: Behavior and monoamine deficits in prenatal and perinatal iron deficiency are not corrected by early postnatal moderateiron or high-iron diets in rats. J Nutr 2012, 142:2040-2049.

37. Felt BT, Beard JL, Schallert T, Shao J, Aldridge JW, Connor JR, Georgieff MK, Lozoff B: Persistent neurochemical and behavioral abnormalities in adulthood despite early iron supplementation for perinatal iron deficiency anemia in rats. Behav Brain Res 2006, 171:261-270.

38. Beard JL, Unger EL, Bianco LE, Paul T, Rundle SE, Jones BC: Early postnatal iron repletion overcomes lasting effects of gestational iron deficiency in rats. J Nutr 2007, 137:1176-1182.

39. Kwik-Uribe $\mathrm{CL}$, Golub MS, Keen CL: Chronic marginal iron intakes during early development in mice alter brain iron concentrations and behavior despite postnatal iron supplementation. J Nutr 2000, 130:2040-2048.

40. Beard J, Erikson KM, Jones BC: Neonatal iron deficiency results in irreversible changes in dopamine function in rats. J Nutr 2003, 133:1174-1179.

41. Nelson C, Erikson K, Pinero DJ, Beard JL: In vivo dopamine metabolism is altered in iron-deficient anemic rats. J Nutr 1997, 127:2282-2288.

42. Kodas E, Vancassel S, Lejeune B, Guilloteau D, Chalon S: Reversibility of $n-3$ fatty acid deficiency-induced changes in dopaminergic neurotransmission in rats: critical role of developmental stage. J Lipid Res 2002, 43:1209-1219.

43. Kodas E, Galineau L, Bodard S, Vancassel S, Guilloteau D, Besnard JC, Chalon S: Serotoninergic neurotransmission is affected by $n-3$ polyunsaturated fatty acids in the rat. J Neurochem 2004, 89:695-702.

44. McEwen BS: Physiology and neurobiology of stress and adaptation: central role of the brain. Physiol Rev 2007, 87:873-904.

45. Ellis KA, Nathan PJ: The pharmacology of human working memory. Int J Neuropsychopharmacol 2001, 4:299-313.

46. Rowe JB, Toni I, Josephs O, Frackowiak RS, Passingham RE: The prefrontal cortex: response selection or maintenance within working memory? Science 2000, 288:1656-1660.

47. Gasbarri A, Cifariello A, Pompili A, Meneses A: Effect of 5-HT (7) antagonist SB-269970 in the modulation of working and reference memory in the rat. Behav Brain Res 2008, 195:164-170.

48. Yehuda S, Rabinovitz S, Carasso RL, Mostofsky DI: Long-lasting cognitive, physiological and hematological effects in rehabilitated, early dietary iron-deficiency adult rats, and improvement by treatment with a mixture of essential fatty acids. Nutr Neurosci 2008, 11:167-171.

49. D'Hooge R, De Deyn PP: Applications of the Morris water maze in the study of learning and memory. Brain Res Brain Res Rev 2001, 36:60-90.

50. Vorhees CV, Williams MT: Morris water maze: procedures for assessing spatial and related forms of learning and memory. Nat Protoc 2006, 1:848-858.

51. Erikson KM, Jones BC, Hess EJ, Zhang Q, Beard JL: Iron deficiency decreases dopamine D-1 and D-2 receptors in rat brain. Pharmacol Biochem Behav 2001, 69:409-418.

52. McNamara RK, Able J, Jandacek R, Rider T, Tso P: Gender differences in rat erythrocyte and brain docosahexaenoic acid composition: role of ovarian hormones and dietary omega-3 fatty acid composition. Psychoneuroendocrinology 2009, 34:532-539.

53. Reeves PG, Nielsen FH, Fahey GC Jr: AIN-93 purified diets for laboratory rodents: final report of the American Institute of Nutrition ad hoc writing committee on the reformulation of the AIN-76A rodent diet. J Nutr 1993, 123:1939-1951.

54. Erikson KM, Pinero DJ, Connor JR, Beard JL: Regional brain iron, ferritin and transferrin concentrations during iron deficiency and iron repletion in developing rats. J Nutr 1997, 127:2030-2038.

55. Folch J, Lees M, Sloane Stanley GH: A simple method for the isolation and purification of total lipides from animal tissues. J Biol Chem 1957, 226:497-509.

56. Lavialle M, Champeil-Potokar G, Alessandri JM, Balasse L, Guesnet P, Papillon C, Pevet P, Vancassel S, Vivien-Roels B, Denis I: An (n-3) polyunsaturated fatty acid-deficient diet disturbs daily locomotor activity, melatonin rhythm, and striatal dopamine in Syrian hamsters. J Nutr 2008, 138:1719-1724.

57. Zimmer L, Delpal S, Guilloteau D, Aioun J, Durand G, Chalon S: Chronic n-3 polyunsaturated fatty acid deficiency alters dopamine vesicle density in the rat frontal cortex. Neurosci Lett 2000, 284:25-28. 
58. Burhans MS, Dailey C, Beard Z, Wiesinger J, Murray-Kolb L, Jones BC,

Beard JL: Iron deficiency: differential effects on monoamine transporters. Nutr Neurosci 2005, 8:31-38.

59. Honig WK: Studies of working memory in the pigeon. In Cognitive processes in animal behaviour. Edited by Hulse SH, Fowler H, Honig WK. Hillsdale N.J: Erlbaum; 1978:211-248.

doi:10.1186/1476-511X-13-97

Cite this article as: Baumgartner et al:: Providing male rats deficient in iron and $\mathrm{n}-3$ fatty acids with iron and alpha-linolenic acid alone affects brain serotonin and cognition differently from combined provision. Lipids in Health and Disease 2014 13:97.

\section{Submit your next manuscript to BioMed Central and take full advantage of:}

- Convenient online submission

- Thorough peer review

- No space constraints or color figure charges

- Immediate publication on acceptance

- Inclusion in PubMed, CAS, Scopus and Google Scholar

- Research which is freely available for redistribution 